مكان يابى جايكًاههاى كنتر ل كننده صفات ايمنى با استفاده از نشانكَرهاى







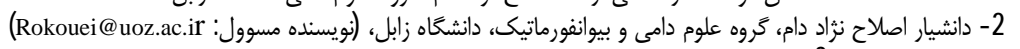







تاريخ دريافت:1398/20 1

























وازههاى كليدى: بلدرجين زاينى، صفات ايمنى، بوت استرايينَى، ايمونوكَلوبولينها






ايمنى ذاتى يك استراتزى دفاعى تكاملى قدئى إيمى استى






















لازم براى شناسايى و مبارزه با ميكروب إنها، بايد تكامل يابن يابند.







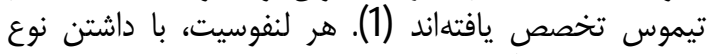







آيانديس جمع مى شوند (1) دينر



رشد و توسعهى روز افزون يرورش طيور به شيوهى متراكم




















طيور در اتحاديه ارويا از سال 2006 ممنوع شده استيك است (12).






















بر روى سيسته ايمنى يرندكان انجام كرفته است إست




همكاران (22) وراثتيذيرى عيار آنتىبادى بر عليه SRBC









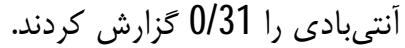











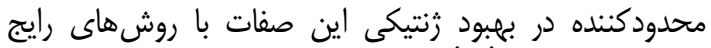





















طريق انتخاب بر بايئ نشانغر ها كار آمدتر مى كند (40)






















در زنوم بلدرجين در مقايسه با مرغ، اطلاعات إنات اندكى در















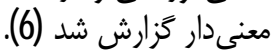




سلامت يرنده و انسان محسوب مى شود و يكى از بايدايدارترين
مفهوم ايمنى همورال بر اساس تجزيه و تحليل فعاليت



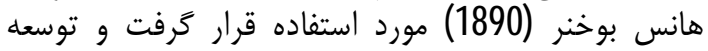




كشتن ميكروار كانيسمه ها هستند.

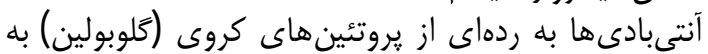











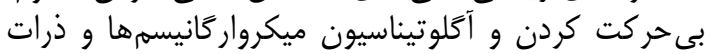

















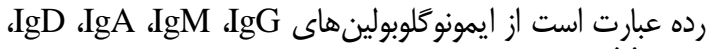







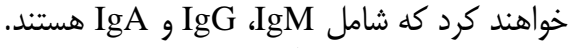



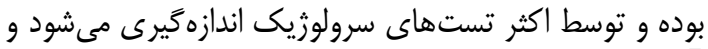

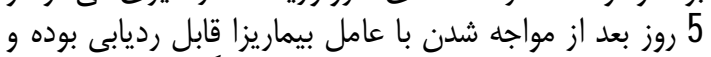


در آينده بهبود وضعيت زنتيكى سيستم ايمنى يرندكان
































درون فاصلهاى براى صفات درصد هتروفيل، لنفوسيت و نسبت نقيت 
شد و جهت ايجاد نسل سوم تعداد 10 جفت از آميختههاى

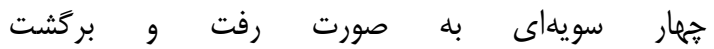

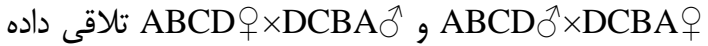
شده و در نهايت از آميزش تصادفى تعداد 20 جفت نر و و ماد ماده


تخمهاى حاصل در طى يك يك دوره

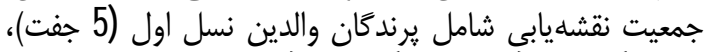





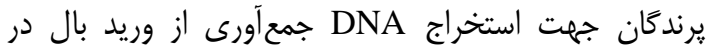





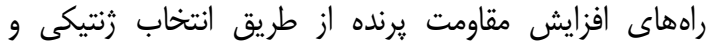





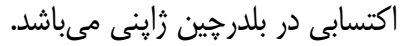



در اجراى يزوهش حاضر از يك جمان جمعيت بلدرجين حاصل


هر سويه شامل: (C) Italian Speckled)، (D) M \& A texas و به صورت جفتى و رفت و (C) Wild


هم تلاقى داده شدند. آميختهاى حاصل از تلاقى دو دو سويه براى توليد نسل دوم استفاده



شكل11 - طرح شماتيك الكَوى جهار نسلى جهت ايجاد جمعيت مورد استفاده در مكان يابى صفات ايمنى در بلدرجين زإينى

Figure 1. Schematic design of a four-generation pattern of crossbred population for QTL mapping of immunity traits in Japanese quail




يايان به تمامى خاهكها مقدار















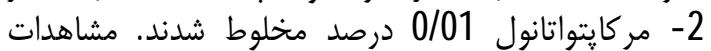






مشاهدات هر خصوصيت در دامنه بين صفر تا 12 قرار خواهد داشت (22). با توجه به آخرين نقشه ييوستخى نشانكرهاى ريزماهواره
از كَلبول قرمز كَوسفند در اين آزمايش به عندان إنهان











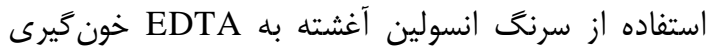





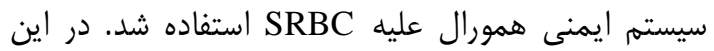





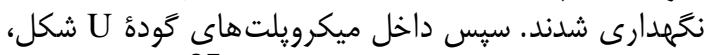


خاهك اول ميزان



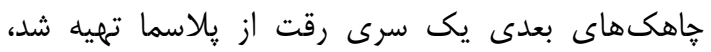


شده مربوط به نشانكرهاى ريزماهواره هستند از الكتروفورز زل






بين آنها به وسيله نرمافزار آناين GridQTL (32) مورد تجزيه و تحليل قرار گرفت.
بلدرجين (18)، يويش زنومى در بخشهايى از كروموزوم 5 با







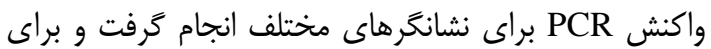



جدول 1 - مشخصات آغازگرهاى مربوط به نشانگرهاى ريزماهواره اى واقع بر روى كروموزوم5 در بلدرجين زإينى Table 1. Characterization of primers related to microsatellite markers located on chromosome 5 in Japanese quail

\begin{tabular}{|c|c|c|c|c|c|}
\hline منبع & يرايمر برَشت & يرايمر رفت & (سانتى اتصراد) & موقعيت & نشانكر \\
\hline \multirow{3}{*}{18} & $\begin{array}{l}5^{\prime} \text {-CGGTAGCATTTCTGACTCCA -3' } \\
\text { ' }\end{array}$ & 5'-GAAGCAGTGACAGCAGAATG -3' & $6(/ 4$ & C & GUJ0049 \\
\hline & 5'-TAGGTGCGAAAATCTCTGAC - $3^{\prime}$ & 5'-GACAAAGTTACAGCTAGGAG -3' & $56 / \equiv$ & 12 & GUJ0059 \\
\hline & $5^{\prime}$-CAGAATATAAAGGTCACAGCC - $3^{\prime}$ & 5'-GCATTTCCATCAGTACAACC -3' & $5 \varepsilon / 7$ & 27 & GUJ0100 \\
\hline
\end{tabular}

عنوان محتملترين مكان QTL در نظر گرفته شد. همجنين،



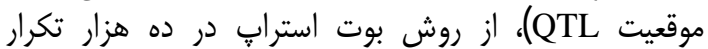

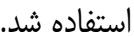

براى تعيين اندازه و تعداد قطعات حاصل از واكنش يليمراز

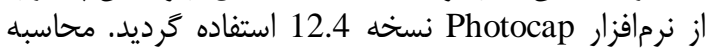
ساختارهاى زنتيكى و جمعيتى شامل فراوانى آللى و زنوتئيى،






GridQTL

هر سه جايخاه واقع بر روى كروموزوم 5 بلدرجين زاينى







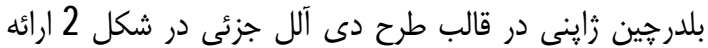
شده است.
مدل آمارى جهت نقشهيابى ثنها شامل مدل افزايشى

$\mathrm{Y}_{\mathrm{ijk}}=\mu+\mathrm{H}_{\mathrm{i}}+\mathrm{S}_{\mathrm{j}}+\mathrm{aP}_{\mathrm{ak}}+\mathrm{e}_{\mathrm{ijk}}$ آلل هاى QTL به شرح ذيل است:























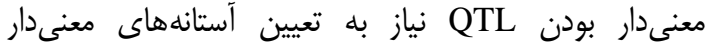



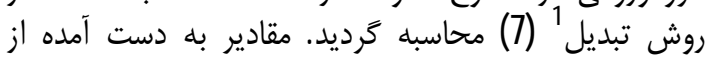

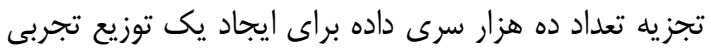








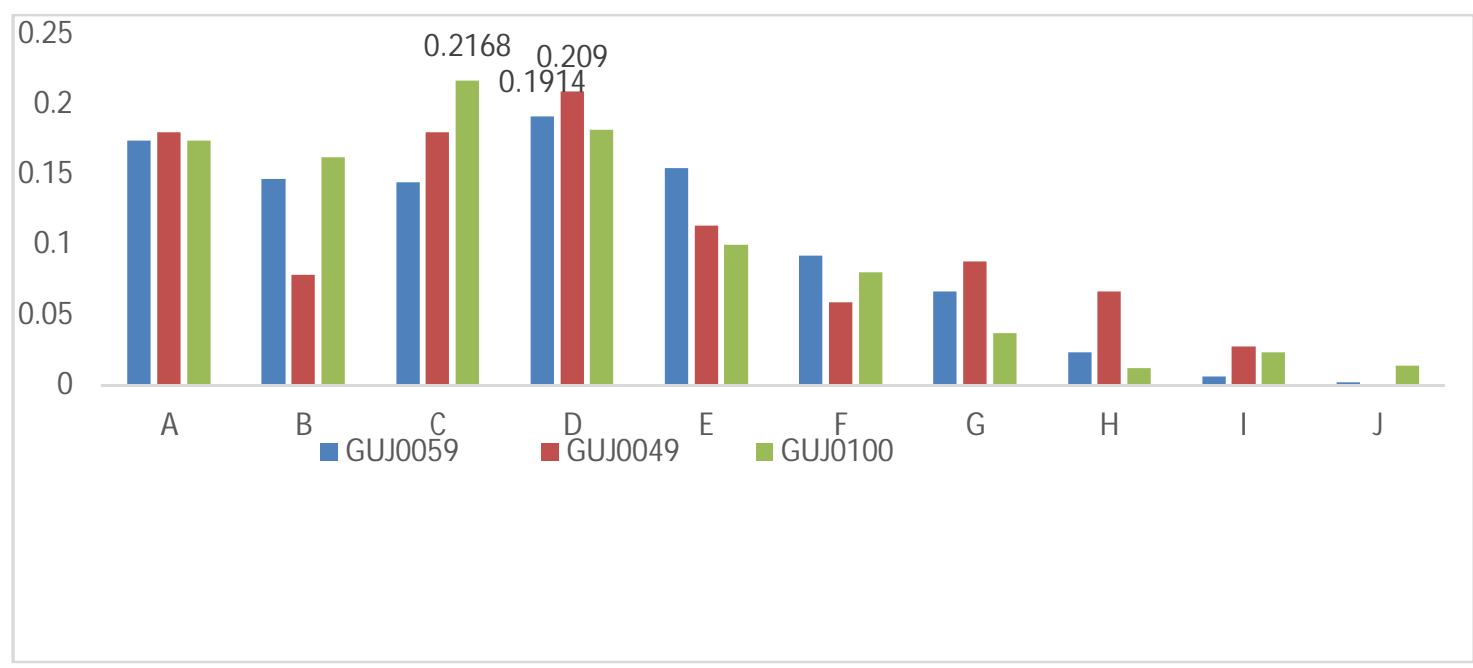

شكل 2 - فراوانى آلل هاى مشاهده شده در سه جايخاه ريزماهوارهاى مورد مطالعه بر روى كروموزوم5 بلدرجين زإينى

Figure 2. Frequency of alleles observed in three microsatellite loci studied on chromosome 5 of Japanese quail










جدول 2 ارائه شده است.
بيشترين فراوانى آللى در دو جايگاه GUJ0059 و و

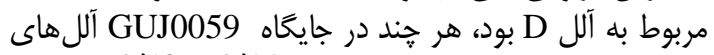







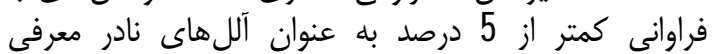
مىشوند در جايخاه GUJ0100 بيشترين فراوانى آللى مربوط ندان


Table 2. Number of observed and effective alleles of the three microsatellite loci located on the chromosome 5 in a crossbred population of four Japanese quail strains

\begin{tabular}{|c|c|c|c|c|}
\hline شاخص شانون & تعداد ألل مؤثر & تعداد آلل مشاهده شده & اندازه جمعيت &  \\
\hline $1 / 9$ & $68=$ & IC & 25E & GUJ0059 \\
\hline $2 / 0 E$ & $\varepsilon / 94$ & $\mathrm{C}$ & 256 & GUJ0049 \\
\hline $1 / 9$ & $6 / 45$ & IC & 256 & GUJ0100 \\
\hline $2 / 01$ & $\epsilon / T$ & c/6/ & 256 & ميانگين \\
\hline
\end{tabular}

محتواى اطلاعات خندشكلى سه جايعاه ريزماهوارهاى واقع بر



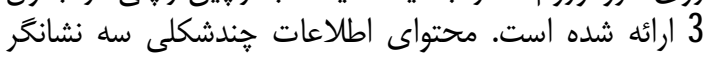






مطالعات ييوستخى زنتيكى هستن





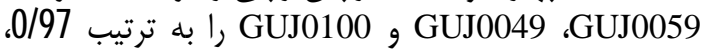
095 و 094 ززارش نمودند ايرانمش و همكاران (14)

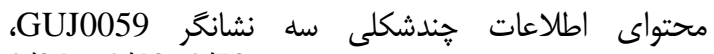

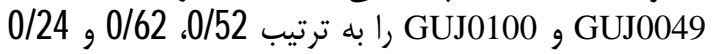

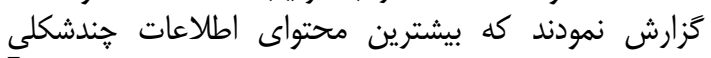
متعلق به نشانگر واقع مىباشد.
تعداد آللهاى مشاهده شده در دو جايياه GUJ0059 و GUJ0100 برابر با 10 و در جايگاه

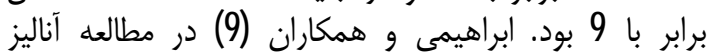







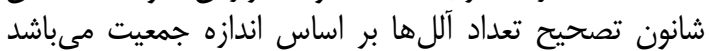





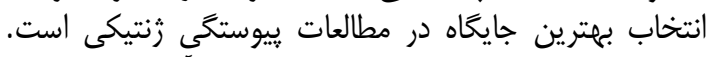

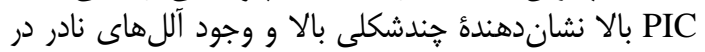

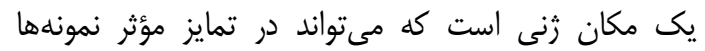

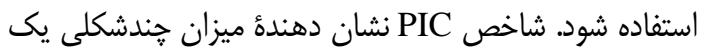

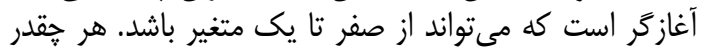

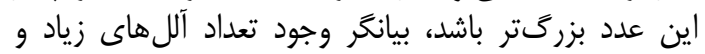

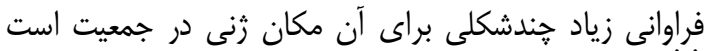


جدول3 - محتواى اطلاعات جندشكلى سه جايكاه ريزماهواره اى واقع بر روى كروموزم5 در جمعيت آميخته4 سويهاى بلدرجين زإينى Table 3. Polymorphism information content of three microsatellite loci located on the chromosome 5 in a crossbred population of four Japanese quail strains

\begin{tabular}{|c|c|c|c|}
\hline محتواى اطلاعات حندشكلى & هتروزيخوسيتى مورد انتظار & هتروزيخوسيتى مشاهده شده & نشانكر \\
\hline C/835 & $\mathrm{C} / 8 \mathrm{~S}$ & $\mathrm{C} / \mathscr{C}$ & GUJ0059 \\
\hline C/8AC & $C / \mathscr{C}$ & $C / 92$ & GUJ0049 \\
\hline$C / 82 E$ & C/\& & C/8/ & GUJ0100 \\
\hline C/834 & C/8 & $C / \mathscr{C}$ & ميانكَين \\
\hline
\end{tabular}

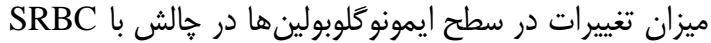

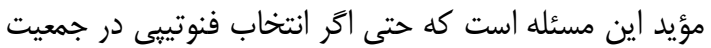

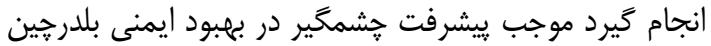

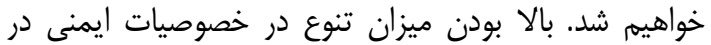

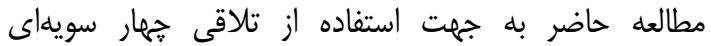

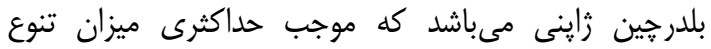

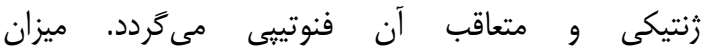

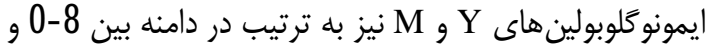

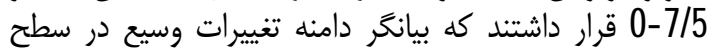

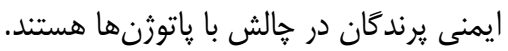

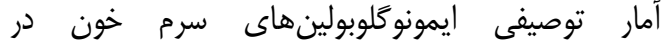

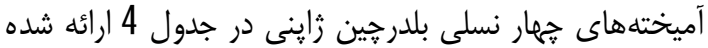

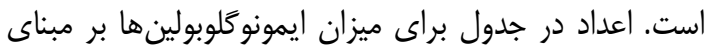

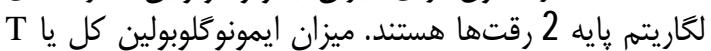

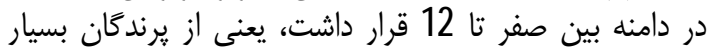

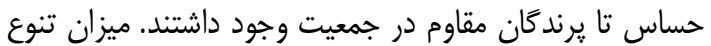

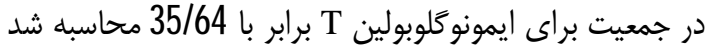

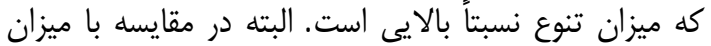

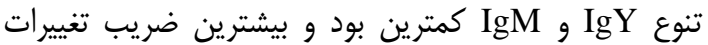

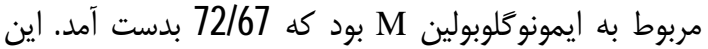

جدول4 - خصوصيات توصيفى ايمونو كلوبولينهاى سرم آميختهاى4 سويهاى بلدرجين زإِى Table 4. Descriptive Characteristics of immunoglobulins serum of four crossbred Japanese Quail

\begin{tabular}{|c|c|c|c|c|c|c|}
\hline ضريب تغييرات & انحراف معيار & حداكثر & حداقل & (لكاريتم دو رقتها) & ت تعداد نمونه & ايمونو كلوبولين \\
\hline 35/64 & $1 / 8$ & T2 & $\mathrm{C}$ & $5 / 2 \varepsilon$ & 200 & IgT \\
\hline $4 / / 15$ & $1 / 6$ & $\bar{\varepsilon}$ & C & $\exists / 4$ & 20 & $\operatorname{IgY}$ \\
\hline$T / 6 /$ & $1 / 31$ & $7 / 5$ & C & ]/BC & 200 & $\mathrm{IgM}$ \\
\hline
\end{tabular}

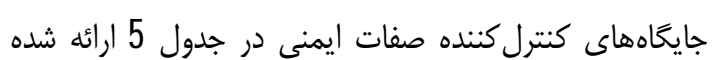

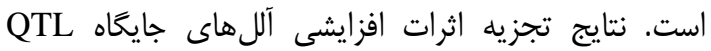

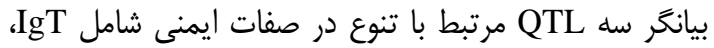
IgM و IgY

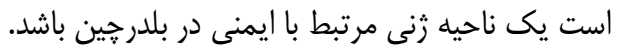

اثرات نوبت هج و جنس يرنده بر هر سه خصوصيت ايمنى

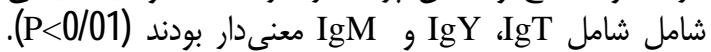

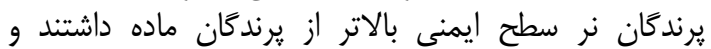
جوجههاى حاصل از هجهاى ابتدايى سطح ايمنى بالاتر نسبت التران

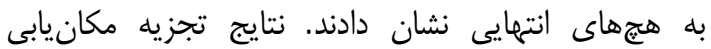

جدول - نتايج تجزيه QTL صفات مرتبط با ايمنى اكتسابى در يك طرح سه نسلى حاصل از تلاقى جهار سويه بلدرجين زإِنى

Table 5. The results of QTL analysis for traits related to acquired immunity in a three-generation design derived from a crossover of four Japanese quail strains

\begin{tabular}{|c|c|c|c|c|c|c|c|}
\hline واريانس (درصد) & $\begin{array}{c}\text { 95\% C.I } \\
\text { حدود اعتماد }\end{array}$ & نزديكتر ين نشانكر & اثرات & Family & $\begin{array}{c}\text { F-value } \\
\text { chromosome-wide } \\
\text { thresholds }\end{array}$ & $\begin{array}{l}\text { موقعيت } \\
\text { (cM) }\end{array}$ & صفت \\
\hline$\varepsilon / 5$ & $2-C$ & GUJ0059 & 35 & I5 & g/gE & $13 / 5$ & IgT \\
\hline 7 & 2-C & GUJ0049 & $5 / 32$ & 巨 & $\epsilon / \mathcal{E}$ & $\varepsilon / \subseteq$ & $\operatorname{IgY}$ \\
\hline I/1 & $27-C$ & GUJ0100 & $4 / 41$ & I & $\mathrm{c} / \mathscr{Q}$ & $14 / 7$ & IgM \\
\hline
\end{tabular}

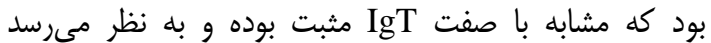

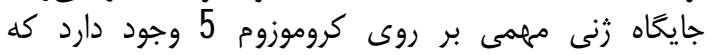

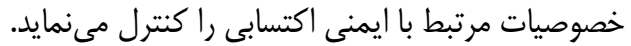

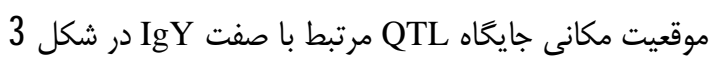
نمايش داده شده است. مكان QTL

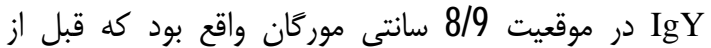

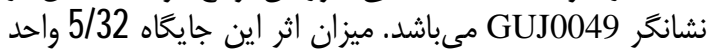




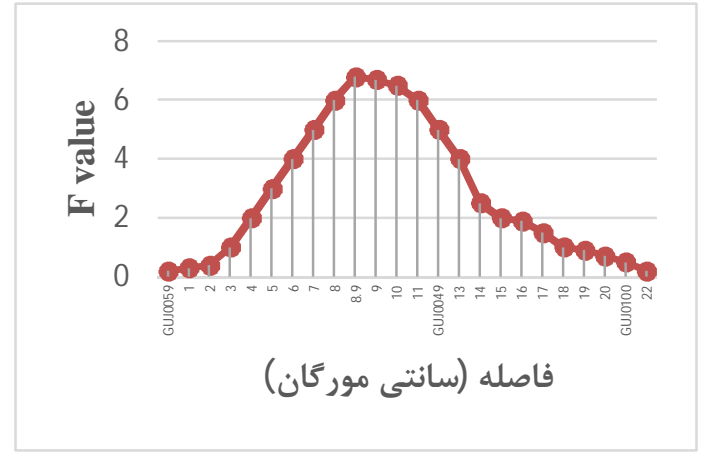

شكل 3 - مكان زنى (QTL) كنترل كننده صفت IgY بر روى كروموزم5 بلدرجين زإينى

Figure 3. QTL mapping of IgY trait on chromosome 5 of Japanese quail

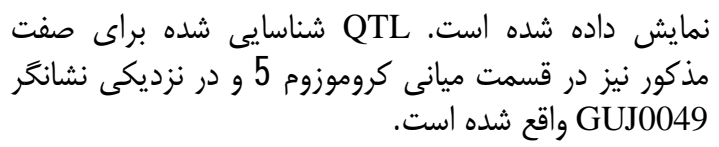

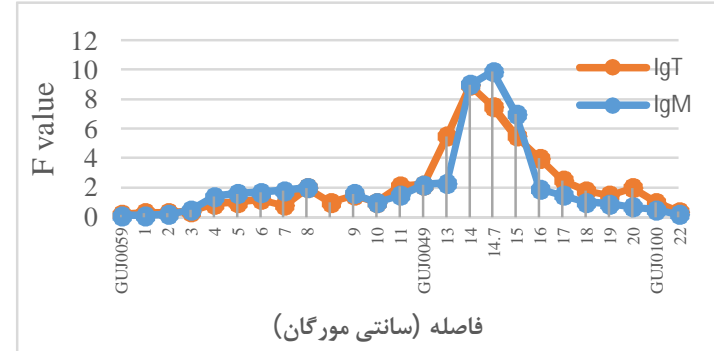

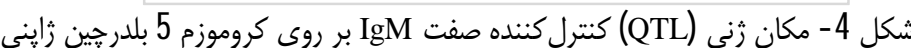

Figure 4. QTL mapping of IgM trait on chromosome 5 of Japanese quail

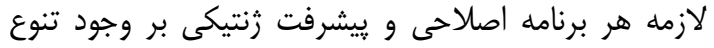

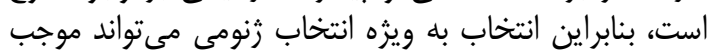

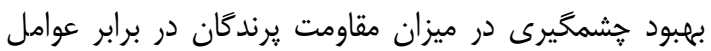

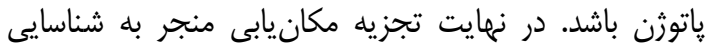

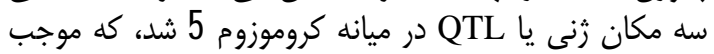

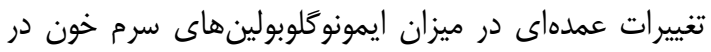

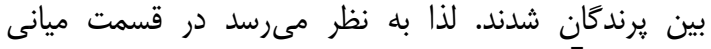

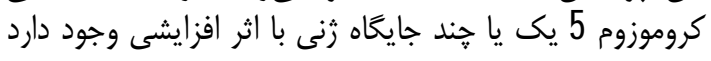

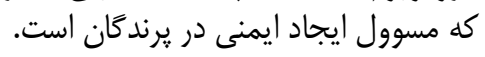

$$
\begin{aligned}
& \text { در شكل } 4 \text { موقعيت مكانى QTL توصيف كننده تنوع در ميزان } \\
& \text { ايمونوكلوبولين IgT نمايش داده شده شده است كه در مجاورت } \\
& \text { نشانخر GUJ0049 واقع شده است. } \\
& \text { نتايج تجزيه QTL براى خصوصيت ايمنى }
\end{aligned}
$$

درصد واريانس به واسطه Qهاى شناسايى شده بر روى

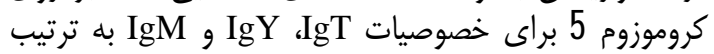
برابر با8/5، 7 و و12/1 درودد واريانس كل بودند. نشانگرهاى واقع بر روى كروموز

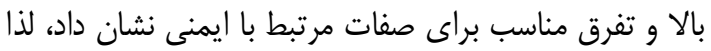

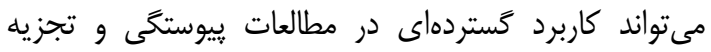

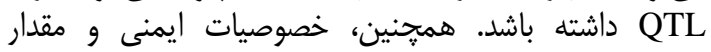

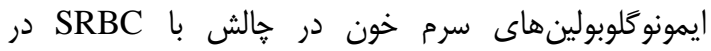
بلدرجين زإينى تنوع بالايى را نشان داد، لذا با توجه به اين اين كه

منابع

1. Abbas, A.K., A.H. Lichtman and S. Pillai. 2014. Basic immunology: functions and disorders of the immune system (Elsevier Health Sciences).

2. Baron, E.E., A.S. Moura, M.C. Ledur, L.F. Pinto, C. Boschiero, D.C. Ruy, K. Nones, E.L. Zanella, M. F. Rosário, D.W. Burt and L.L. Coutinho. 2010. QTL for percentage of carcass and carcass parts in a broiler x layer cross. Animal Genetics, 42(2): 117-124.

3. Botestein, D., R.L. White, M. Skolnick and R.W. Davis. 1980. Construction of a genetic linkage map in man using restriction fragment lrngth polymorphisms. American. Journal of Human Genetic, 32: 314-331.

4. Bovenhuis, H., H. Bralten, M.G. Nieuwland and H.K. Parmentier. 2002. Genetic parameters for antibody response of chickens to sheep red blood cells based on a selection experiment. Poultry Science, 81(3): 309-315.

5. Buchanan, F.C. and T.D. Thue. 1998. Intra-breed polymorphic information content of microsatellites in cattle and sheep. Canadian Journal of Animal Science, 78: 425-428. 
6. Charati, H., A. Esmailizadeh, R. Jabari and A. Ayatollahi Mehrgardi. 2014. Mapping quantitative trait loci affecting leukocytes, body temperature and tonic immobility in Japanese quail. Novin Genetic, 9(1): 57-66 (In Persian).

7. Churchill, G.A. and R.W. Doerge. 1994. Empirical threshold values for quantitative trait mapping. Genetics, 138: 963-971.

8. Davison, F., B. Kaspers, K.A. Schat and P. Kaiser. 2011. Avian immunology (Academic Press).

9. Ebrahimi, K., G.R. Dashab, H. Faraji- Arough, A. Maghsoudi and M. Rokouei. 2019. Genome scan of Japanese quail chromosome 5 for detecting of QTLs of growth traits. Animal Production Research, (In press) (Persian) doi: 10.22124/AR.2019.10859.1333

10. Esmailizadeh, A.K., A. Baghizadeh and M. Ahmadizadeh. 2012. Genetic mapping of quantitative trait loci affecting body-weight on chromosome 1 in a commercial strain of Japanese quail. Animal Production Science, 52: 64-68.

11. Frost, A.J. and J.B. Woolcock. 1991. Antibiotics and animal production. In: Microbiology of Animals and Animal Products, New York, NY: Elsevier, pp: 181-194.

12. Garcia, V., P.C. Gregori, F. Hernandez, M.D. Megias and J. Madrid. 2007. Effect of formic acid and plant extracts on growth, nutrient digestibility, intestine mucosa morphology, and meat yield of broilers. Journal of Applied Poultry Research, 16: 555-562.

13. Gavora, J.S. 1993. Genetic control of disease and disease resistance in poultry. Pages 231-241 in: Manipulation of Avian Genome. R.J. Etches and A.M. Verrinder-Gibbins, ed. CRC Press, Boca Raton, FL.

14. Iranmanesh, M., A. Esmailizadeh, M. R. Mohammad abadi and S. Sohrabi. 2017. Identification of quantitative trait loci affecting average daily gain and Kleiber ratio on chromosome 5 in an F2 population of Japanese quail. Animal Production Research, 5(4): 12-22 (In Persian).

15. Jabbari, R., A.K. Esmailizadeh, H. Charati, M.R. Mohammadabadi and S.S. Sohrabi. 2014. Identification of QTL for live weight and growth rate using DNA markers on chromosome 3 in an F2 population of Japanese quail. Molecular Biology Reports, 41: 1049-1057.

16. Janeway, C.A. 2001. How the immune system works to protect the host from infection: a personal view. Proceedings of the National Academy of Sciences, 98: 7461-7468.

17. Janeway, C., P. Travers, M. Walport and M. Shlomchik. 2004. Immunobiology. Garland Science. New York.

18. Kayang, B., A. Vivnal, M. Inoue-Murayama, M. Miwa, J.L. Monvoisin, S. Ito and F. Minvielle. 2004. A first-generation microsatellite linkage map of the Japanese quail. Animal genetics, 35: 195-200.

19. Liu, K. and S.V. Muse. 2005. PowerMarker: An integrated analysis environment for genetic marker analysis. Bioinformatics, 21: 2128-2129.

20. Lwelamira, J. and A. Katule. 2004. Genetic determination of immune responses to Newcastle disease virus vaccine in chickens. Bulletin of Animal Health and Production in Africa, 52: 186-197.

21.Lwelamira, J., G.C. Kifaro and P.S. Gwakisa. 2009. Genetic parameters for body weights, egg traits and antibody response against Newcastle Disease Virus (NDV) vaccine among two Tanzania chicken ecotypes. Tropical Animal Health and Production, 41(1): 51-59.

22. Martin, A., E.A. Dunnington, W.B. Gross, W.E. Briles, R.W. Briles and P.B. Siegel. 1990. Production traits and alloantigen systems in lines of chickens selected for high or low antibody responses to sheep erythrocytes. Poultry Science, 69: 871-878.

23. Metchnikoff, E. 1905. Immunity in infective diseases (University Press).

24. Miller, S. A., D.D. Dykes and H.F. Polesky. 1998. A simple salting out procedure for extracting DNA from human nucleated cells. Nucleic Acids Research, 16: 12-15.

25. Minvielle, F., B. Kayang, M. Inoue-Murayama, M. Miwa, A. Vignal, D. Gourichon, A. Neau, J. Monvoisin and S. Ito. 2005. Microsatellite mapping of QTL affecting growth, feed consumption, egg production, tonic immobility and body temperature of Japanese quail. BMC Genomics, 6: 87.

26. Moradian, H., A. Esmailizadeh and M. Mohammadabadi. 2015. Microsatellite mapping of quantitative trait loci associated with carcass traits on chromosome 1 in Japanese quail. Animal Production, 15(2): 89-99 (In Persian).

27. Navani, N.K., P. Jain, S. Gupta, B.S. Sisodia and S. Kumar. 2002. A set of cattle microsatellite DNA markers for genome analysis of riverine buffalo (Bubalus bubalis). Animal Genetics, 33(2): 149-154.

28. Nobakht, A., J. Norany and A.R. Safamher. 2011. The effects of different amount of Mentha pulegium L. (pennyroyal) on performance, carcass traits, hematological and blood biochemical parameters of broilers. Journal of Medicinal Plants Research, 5: 3763-3768.

29. Peterson, A.T., J. Soberón and V. Sánchez-Cordero. 1999. Conservatism of ecological niches in evolutionary time. Science, 285: 1265-1267.

30. Pinard, M.H., J.A. M. van Arendonk, M.G.B. Nieuwland and A.J. Van Der Zijpp. 1992. Divergent selection for immune responsiveness in chickens: Estimation of realized heritability with an animal model. Journal of Animal Science, 70: 2986-2993. 
31. Ponte, P. and C. Rosado. 2008. Pasture intake improve the performance and meat sensory attributes of free-range in broilers. Poultry Science, 87: 71-79.

32. Seaton, G., J. Hernandez, J.A. Grunchec, I. White, J. Allen, D.J. De Koning, W. Wei, D. Berry, C. Haley and S. Knott. 2006. GridQTL: A Grid Portal for QTL Mapping of Compute Intensive Datasets. Proceedings of the $8^{\text {th }}$ World Congress on Genetics Applied to Livestock Production, Belo Horizonte, Brazil.

33. Singh, P., S. Kumar, H.N. Singh and D.P. Singh. 2010. Genetics of immunocompetence traits in Aseel native chicken. Journal of Applied Animal Research, 37(2): 229-231.

34. Sivaraman, G.K., S. Kumar, V.K. Saxena, N.S. Singh and B.M. Shivakumar. 2005. Genetics of immunocompetent traits in a synthetic broiler dam line. British Poultry Science, 46(2): 169-174.

35. Sohrabi, S.S., A.K. Esmailizadeh, A. Baghizadeh, H. Moradian, M.R. Mohammadabadi, N. Askari and E. Nasirifar. 2012. Quantitative trait loci underlying hatching weight and growth traits in an F2 intercross between two strains of Japanese quail. Animal Production Science, 52(1): 1012-1018.

36. Uemoto, Y., S. Sato, S. Odawara, H. Nokata, Y. Oyamada, Y. Taguchi, S. Yanai, O. Sasaki, H. Takahashi, K. Nirasawa and E. Kobayashi. 2009. Genetic mapping of quantitative trait loci affecting growth and carcass traits in F2 intercross chickens. Poultry Science, 88(3): 477-482.

37. Wijga, S., H.K. Parmentier, M.G.B. Nieuwland and H. Bovenhuis. 2009. Genetic parameters for levels of natural antibodies in chicken lines divergently selected for specific antibody response. Poultry Science, 88(9): 1805-1810.

38. Yalcin, S., I. Oguz and S. Otles. 1995. Carcass characteristics of quail (Coturnix Coturnix Japonica) slaughtered at different ages. British Poultry Science, 36: 393-399.

39. Yeh, F.C., R. Yang and T. Boyle. 1999. POPEGENE. Version 1.31. Microsoft Window-based Freeware for Population Genetic Analysis, University of Alberta. Edmonton.

40. Zane, L., L. Bargelloni and T. Patarnello. 2002. Strategies for microsatellite isolation: a review. Molecular Ecology, 11(1): 1-16. 


\title{
Mapping of Quantitative Trait Loci for Immunity Traits by Microsatellite Markers on chromosome 5 in Japanese Quail
}

\author{
Raheleh Khanegir $^{1}$, Mohammad Rokouei ${ }^{2}$, Hadi Faraji Arough $^{3}$, Ali Maghsoudi ${ }^{4}$ and
} Gholam Reza Dashab

1- Graduted M.Sc. Student, of Animal Breeding, Department of Animal Science, University of Zabol 2- Associate professor of Animal Breeding, Department of Animal Science and Bioinformatics, University of Zabol (Corresponding author: rokouei@uoz.ac.ir)

3- Assistant professor of Animal Breeding and Genetic, Department of Domestic research, University of Zabol 4- Assistant professor of Animal Breeding, Department of Animal Science and Bioinformatics, University of Zabol 5- Associate professor of Animal Breeding and Genetic, Department of Animal Science, University of Zabol Received: November 11, $2019 \quad$ Accepted: February 8, 2020

\begin{abstract}
Immune traits are very important because of their direct relationship with the growth traits and the economic value of quail breeding. The purpose of this study was to investigate the part of the Japanese quail genome in order to detect QTL affecting on immunity traits using a fourgeneration crossover design. For this purpose, four strains of A and M Texas, Wild, Italian Speckled and Tuxedo Japanese quails were mated as reciprocal crossed for creating the first generation. Then, another generation, including the second, third and fourth generations were created from the crossing of the first generation hybrid birds. Phenotypic data included traits related humoral immunity of birds, including T, M and Y immunoglobulins. The third and fourth generation parents and all birds from the fourth generation parents were genotyped for three microsatellite markers located on the chromosome 5. QTL analysis was performed by interval mapping based on regression with GridQTL software. Three adjacent QTLs in the middle of chromosome 5 for the three IgT, IgM, and IgY were identified at the positions 13.5, 8.9 , and $14.7 \mathrm{~cm}$ near to marker GUJ0049, respectively. Therefore, the results showed that there was at least one gene with a major effect on immunity traits adjacent to the marker GUJ0049, and adding the information of the mentioned marker genotypes to the statistical models could improve the accuracy of prediction of breeding values for immunity traits in quail.
\end{abstract}

Keywords: Japanese quail, Immunity traits, Bootstraping, Immunoglobulins 